\title{
Potential Effect of Mucilage of Calophyllum inophyllum Nuts on Some Metabolic Syndrome Features Associated with a High-fat/High-sucrose Diet in Wistar Rats
}

\author{
William Dakam ${ }^{1,2}$, Erika L. Asseng Azombo ${ }^{1}$, Christine F. Nyangono Biyegue ${ }^{2,3}$, Emmanuel A. Mpondo \\ Mpondo $^{1} \&$ Julius E. Oben ${ }^{2}$ \\ ${ }^{1}$ Faculty of Medicine and Pharmaceutical Sciences, University of Douala, Cameroon \\ ${ }^{2}$ Laboratory of Nutrition and Nutritional Biochemistry, University of Yaoundé 1, Cameroon \\ ${ }^{3}$ Advanced Teacher Training College for Technical Education (ENSET), University of Douala, Cameroon \\ Correspondence: William Dakam, Faculty of Medicine and Pharmaceutical Sciences, University of Douala, P.O. \\ Box 3342 Douala, Cameroon. Tel: 237-699-983-800. E-mail: wildakam@yahoo.fr
}

Received: October 30, 2020

Accepted: December 16, 2020 Online Published: December 22, 2020

doi:10.5539/jfr.v10n1p14

URL: https://doi.org/10.5539/jfr.v10n1p14

\begin{abstract}
Metabolic syndrome (MetS) is a multi-faceted condition involving dyslipidemia, hyperglycemia, and overweight. The present work investigates the effect of mucilage of Calophyllum inophyllum nuts on body weight, plasma glucose, and plasma lipids in an animal model. Firstly, male Wistar rats were fed a high-fat/high sucrose (HFS) diet made of standard laboratory chow enriched with sucrose and egg yolk (caloric content: fats: 33.20\%; sucrose: $21.30 \%$ ) for 33 days. Thereafter, they were divided into groups of five animals, each group receiving one of the following by oral route daily for 14 days: distilled water (HFS-Ctrl), mucilage at doses of 250 or 500 $\mathrm{mg} / \mathrm{kg}$ body weight (HFS-Ci250 and HFS-Ci500 respectively). The body weight of rats was measured at 3-day intervals. Fasting plasma glucose, oral glucose tolerance, and plasma lipid profile were assessed at the end of the study and cardiovascular risk indices were calculated. Mucilage treatment caused a significant decrease in body weight in groups HFS-Ci250 $(-8.56 \%, p<0.05)$ and HFS-Ci500 $(-14.27 \%, p<0.05)$ in comparison with the HFS-Ctrl group. HFS-fed rats treated with mucilage had an improved oral glucose tolerance with total incremental plasma glucose significantly lower than that of the HFS-Ctrl group. Mucilage-treated rats had significantly lower plasma total cholesterol, LDL-cholesterol, and triglycerides as well as higher HDL-cholesterol $(+96.29 \%, p<0.05)$ which led to lower values of cardiovascular risk indices. Our results suggest that mucilage obtained from Calophyllum inophyllum nuts may find applications in the management of human metabolic syndrome by addressing its features such as obesity, hyperglycemia, and dyslipidemias.
\end{abstract}

Keywords: blood glucose, blood lipids, body weight, Calophyllum inophyllum, metabolic syndrome, mucilage

\section{Introduction}

Metabolic syndrome (MetS) is commonly defined as a cluster of mild disorders resulting from impairments in carbohydrate metabolism, lipid metabolism, and/or vascular system (Bonnet \& Laville, 2005). These disorders mostly linked to overweight and obesity are responsible for several metabolic (e.g. diabetes mellitus) or cardiovascular (e.g. stroke) diseases (Bonnet \& Laville, 2005). Cutoffs for MetS diagnosis may differ widely depending on countries or regulatory agencies like WHO (Alberti \& Zimmet, 1998), NCEP-ATP III (NCEP, 2001), EGIR (Wood et al., 1998), and AHA (Grundy et al., 2005). However, diagnosis tools tend to be quite uniform worldwide and include at least three of the following: high fasting blood glucose, impaired glucose tolerance, hypertension, obesity, and high fasting blood lipids (Eckel, Alberti, Grundy \& Zimmet, 2010; Alberti, Zimmet \& Shaw, 2005). MetS-linked pathologies or complications such as type 2 diabetes and coronary heart diseases are nowadays ranked among the leading causes of mortality around the globe (Bonnet \& Laville, 2005). Prevalence of overweight and obesity continued to rise worldwide while diabetes caused 1.43 million deaths in 2016, which represent an increase of $31.1 \%$ from the rate in 2006 (GBD Group, 2017). In these mortality figures, smoking and poor diet remained the leading risk factors of ill health (GBD Group, 2017).

The 'poor diet' association with MetS has been considered for decades, with different components of the diet being pointed at different times. Consumption of macronutrients such as carbohydrates and fats has dominated the global 
'risk-foods' debate (Dehghan et al., 2017). In many countries, due to urbanization and food industry marketing, the intake of refined, fat, and/or sugar-sweetened foods and beverages is high and still increasing in both adults and children (Singh et al., 2015; Kearney, 2010). Moreover, the association of high consumption of such foods with the development of MetS, obesity, type 2 diabetes as well as cardiovascular diseases has been evidenced throughout the world (Dehghan et al., 2017; Chan et al., 2014; Malik et al., 2010; Kuo et al., 2008). It is anticipated that the worldwide prevalence of MetS and its co-morbidities would increase in the upcoming years. Therefore, the search for available and cost-efficient therapies that could address MetS as a whole or its features considered individually remains crucial.

Mucilages are polysaccharide complexes formed from sugar and uronic acid units. They belong to the water-soluble dietary fibers category and are obtained mainly from seeds, nuts, and other plant parts (Divekar, Kalaskar, Chougule, Redasani \& Baheti, 2010). Like other water-soluble dietary fibers, mucilages yield viscous solutions and gels when in contact with water molecules and subsequently increase intestinal viscosity (Papathanasopoulos \& Camilleri, 2010). This property allows mucilages and other soluble fibers to have favorable effects on MetS individual features. Indeed, several studies have shown clearly that mucilages and other soluble dietary fibers occurring in plants like fenugreek, guar, or okra can alleviate hyperglycemia (Chukwuma, Islam \& Amonsou, 2018; Butt, Shahzadi, Sharif \& Nasir, 2007; Dakam, Kuate, Azantsa \& Oben, 2007), hyperlipidemia (Butt et al., 2007; Dakam et al. 2007; Enzi et al., 1980) and excess body fat (Butt et al., 2007; Dakam et al. 2007; Enzi et al., 1980). Therefore, it has been suggested that mucilages and other water-soluble fibers may be viewed as an interesting and cost-effective approach in tackling the growing incidence of MetS (Papathanasopoulos \& Camilleri, 2010). In this context, the search for locally available sources of water-soluble dietary fibers in any part of the world should be encouraged to provide people with affordable MetS prevention/management strategies.

Calophyllum inophyllum commonly known as tamanu or mastwood is a plant of the Guttifereae family found in East Africa, tropical Asia, Northern Australia, and islands in the Pacific and Indian oceans (Damon, 2016). The plant is used by people from these areas for many purposes. For instance, nuts have been highly valued for their oil in the treatment of various health conditions such as rheumatism, pruritus, inflammation, bacterial infections, and wounds (Dweck and Meadows, 2002). Throughout the last four decades, several scientific studies provided evidence of beneficial properties linked to Calophyllum inophyllum: anti-inflammatory (Saxena et al., 1982; Bhalla et al., 1980), antimicrobial (Yimdjo et al., 2004), cytotoxic (Yimdjo et al., 2004), diuretic (Schultes \& Raffauf, 1990), anticancer (Itoigawa et al., 2001; McKee et al., 1998), inhibitory effects on HIV-1 virus reverse transcriptase (Ishikawa, 2002; Xu et al., 1999; Spino, Dodier \& Sotheeswaran, 1998), anti-ulcer (Dweck \& Meadows, 2002) and even insect repellent (Hieu, Kim, Kwon \& Ahn, 2010). These facts show clearly that indigenous populations from the abovementioned parts of the world as well as scientists have been focusing essentially on oil derived from $C$. inophyllum nuts. We have found no report on the therapeutic use of the defatted residue as it is generally discarded after oil extraction from nuts. However, defatted nuts and kernels are often rich in mucilages and other water-soluble polysaccharides that could have valuable input in MetS management as mentioned previously (Ngondi, Fossouo, Djiotsa \& Oben, 2006; Smith, 2003). Therefore, we investigate the possibility of using $C$. inophyllum mucilage as an effective agent of MetS management in an animal model for the first time.

\section{Methodology}

\subsection{Experimental Animals}

Male rats of Wistar strain bred in our laboratory were used in this study. They were 12-weeks old, weighing $180-200 \mathrm{~g}$, and maintained in cages under controlled conditions $\left(25^{\circ} \mathrm{C}, 12: 12\right.$-h dark/light cycle) with free access to food and water. Animal experiments were conducted following the internationally accepted principles for laboratory animal use and care (United States National Institutes for Health publication no. 85-23, revised in 1985). Ethical approval was obtained from the Institutional Ethics Committee for Research of the University of Douala ( $\mathrm{n}^{\circ} 1260$ CEI-UDo/02/2018/T).

\subsection{Plant Material Harvesting and Processing}

C. inophyllum fruits were harvested between November and December 2017 in the City of Limbe, South-West Region of Cameroon. Harvested specimens were identified by Dr. Barthelemy Tchiengue at the Cameroon National Herbarium in Yaoundé, Cameroon (by comparison with specimen $\mathrm{n}^{\circ}$ 50376/HNC). Kernels were removed manually from the fruits and shelled to obtain the nuts that were dried in an oven at $40^{\circ} \mathrm{C}$ till constant weight and ground into a fine powder. Nut powder was kept in opaque flasks. 


\subsection{Mucilage Extraction}

Mucilage was extracted according to the procedure described by Divekar et al. (2010) with some modifications. In brief, nut powder was defatted exhaustively by successive 48-h macerations in hexane at room temperature with a dry matter/liquid ratio of $20 \mathrm{~g}$ per $100 \mathrm{ml}$. The resulting macerates were filtered using $\mathrm{n}^{\circ} 2$ filter paper. Filtrates were concentrated under vacuum using a rotary evaporator (R-205D type Fulton) to recover solvent that was used for subsequent macerations. The defatted solid residue was allowed to dry on a plate at room temperature and was stored in a sealed and opaque jar.

Twenty-five grams of defatted solid residue were homogenized with $500 \mathrm{ml}$ of distilled water in an Erlenmeyer-type flask. The mixture was heated to $50^{\circ} \mathrm{C}$ for 4 hours in a water bath, cooled, and filtered with filter paper $\left(\mathrm{n}^{\circ} 2\right)$. Then, $700 \mathrm{ml}$ of $90 \%$ ethanol were added to the filtrate and the homogenized mixture was centrifuged at $3000 \mathrm{rpm}$ for 10 minutes. The resulting pellet containing mucilage was collected, dried on filter paper, and kept in an opaque flask.

\subsection{Animal Study}

\subsubsection{Phase 1: Differential Feeding}

Thirty adult male rats were fed for 33 days with either standard laboratory diet (SD, $n=5$ ) or high-fat/sucrose diet (HFS, $n=25$ ) made of standard laboratory diet mixed with sucrose (Sosucam, Yaounde, Cameroon) and dried chicken egg yolk in proportions 34:40:26 (w:w:w). Nutrient and energy contents of both diets are presented in Table 1. The standard laboratory diet was the Laboratory Rodent Diet 5001 (LabDiet, St. Louis, MO, USA). Nutrient and energy content of the HFS diet was calculated using data provided by LabDiet for standard laboratory diet and by USDA Nutrient Database for dried chicken egg yolk. All rats were provided with food and drinking water ad libitum. Body weight was monitored every three days for each rat.

Table 1. Composition and energy content of standard laboratory diet (SD) and high-fat /high-sucrose diet (HFS)

\begin{tabular}{lll}
\hline Composition & Standard diet $^{1}$ & HFS diet $^{2}$ \\
\hline Proteins (\%) & 24.10 & 16.84 \\
Fats (\%) & 6.40 & 16.65 \\
Carbohydrates (\%) & 48.70 & 58.52 \\
Sucrose (\%) & 3.15 & 41.07 \\
Fibers (\%) & 5.20 & 1.76 \\
Minerals (\%) & 6.90 & 2.69 \\
Other nutrients (\%) & 8.70 & 3.54 \\
Energy content $^{\mathbf{3}}$ (kcal/100g) & 336.20 & 451.23 \\
Calories provided by & & \\
Proteins (\%) & 28.67 & 14.93 \\
Fats (\%) & 13.38 & 33.20 \\
Carbohydrates (\%) & 57.95 & 51.87 \\
Sucrose (\%) & 1.83 & 21.30 \\
\hline bed by LabDiet (St. Louis, MO, USA) for Laboratory Rodent Diet (5001).
\end{tabular}

${ }^{1}$ Composition as described by LabDiet (St. Louis, MO, USA) for Laboratory Rodent Diet (5001).

${ }^{2}$ Made by mixing standard laboratory diet with sucrose and dried chicken egg yolk (34:40:26 per $100 \mathrm{~g}$ respectively). Nutrient composition established using the USDA Nutrient Database.

${ }^{3}$ Calculated as the sum of decimal fractions of proteins, fats, and carbohydrates $\times 4,9,4 \mathrm{kcal} / \mathrm{g}$ respectively.

\subsubsection{Phase 2: Study of Metabolic Effects of C. inophyllum Mucilage}

In the second phase, SD-fed rats were used as negative controls and remained on the same diet as in phase 1. HFS-fed rats were divided into five groups of five individuals each and remained on HFS diet except for one group (HFS-Sat) which was reverted to standard diet and served as a satellite to monitor persistence or reversibility of any metabolic disturbance brought about by HFS diet. Fenugreek galactomannan was used as reference soluble dietary fiber and was administered to a group of HFS-fed rats (HFS-Fg500). Treatment doses (250 and $500 \mathrm{mg} / \mathrm{kg}$ ) were determined according to a previous study of metabolic effects of fenugreek galactomannan in rodents (Dakam et al., 2007). The experimental scheme is summarized below:

SD-Ctrl: standard laboratory diet + distilled water

HFS-Ctrl: high-fat/high-sucrose diet + distilled water 
HFS-Sat: standard laboratory diet + distilled water

HFS-Ci250: high-fat/high-sucrose diet $+C$. inophyllum nut mucilage at $250 \mathrm{mg} / \mathrm{kg}$

HFS-Ci500: high-fat/high-sucrose diet $+C$. inophyllum nut mucilage at $500 \mathrm{mg} / \mathrm{kg}$

HFS-Fg500: high-fat/high-sucrose + fenugreek galactomannan at $500 \mathrm{mg} / \mathrm{kg}$

Distilled water, nut mucilage, and fenugreek galactomannan were administered to rats by a single daily oral gavage over 14 days. As in phase 1, all rats had free access to food and drinking water, and body weight was recorded every three days. On day 13 , an oral glucose tolerance test (OGTT) was carried out in rats from all groups. In this regard, rats were made fast for $12 \mathrm{~h}$ before the test. For each rat, fasting blood glucose was determined by depositing a single blood drop (collected from the tail tip) on a test strip inserted in a FreeStyle Lite ${ }^{\circledR}$ glucometer (Abbott Laboratories, Illinois, USA). A glucose solution $(2 \mathrm{~g} / \mathrm{kg}$ bw) was administered to all animals by oral gavage. Blood glucose was subsequently measured for each rat at time points $30,60,90$, and 180 min following glucose administration.

\subsubsection{Samples Preparation}

At the end of phase 2, all rats were anesthetized with $\alpha$-ketoglutarate/ketamine combination and sacrificed. Blood from the jugular vein was collected in heparinized tubes and centrifuged at $3000 \mathrm{rpm}$ for 10 minutes. Plasma was collected in Eppendorf tubes and kept at $-20^{\circ} \mathrm{C}$ for subsequent biochemical analyses.

\subsection{Analytical Techniques}

Blood glucose was assessed by the glucose oxidase method using test strips and a one-touch glucometer from Abbott (Abbott Laboratories, Illinois, USA). Plasma total incremental glucose (TIG) during the oral glucose tolerance test was calculated after correction for the baseline (time zero) as the sum of changes in glycemia following glucose intubation according to the following formula:

$$
T I G=\sum_{i=0}^{t}\left(\left[\text { glycemia }_{i}-\left[\text { glycemia }_{0}\right)(\text { Madar, 1989). }\right.\right.
$$

The relative glycemic index (RGI) was calculated as the ratio of TIG in a given group to the TIG in SD-Ctrl group multiplied by 100 :

$$
R G I=\frac{T I G_{x}}{T I G_{S D C t r l}} \times 100(\text { Dakam } \text { et al., 2009). }
$$

All measurements of plasma total cholesterol (TC), HDL-cholesterol (HDL-c) and triglycerides (TG) concentrations were performed using commercially available test kits produced by Chronolab (Zug, Switzerland). LDL-cholesterol (LDL-c) concentrations were determined by calculation (Friedewald, Levy \& Frederickson, 1972). Cardiovascular risk indices were calculated after conversion of lipid profile values into $\mathrm{mmol} / \mathrm{l}$ as follows: TC/HDL-c, LDL-c/HDL-c, and TG/HDL-c.

\subsection{Statistical Analysis}

Results are expressed as means \pm standard deviation. Statistical analysis was carried out using Student's $t$-test for comparing body weight variations between SD and HFS groups in phase 1. One-way analysis of variance (ANOVA) followed by Duncan's Multiple Range Test (DMRT) was used for multiple comparisons in phase 2. All statistical analyses were performed using the SPSS for Windows software, version 22.0 (SPSS Inc., Chicago, IL, USA). $P$-values less than 0.05 were considered significant.

\section{Results}

\subsection{Effect of High-fat/High-sucrose Diet (HFS) on Body Weight Gain of Rats}

Figure 1a depicts the body weight gain in rats fed either the standard diet (SD) or the high-fat/high-sucrose diet (HFS) over 33 days (phase 1). Body weight gain was significantly higher in HFS-fed rats than in SD-fed rats from day 6 to day 33. At the end of phase 1, weight gain was $22.86 \%$ higher in HFS-fed rats than in SD-fed rats $(p<0.05)$.

\subsection{Effect of Mucilage Treatment on Body Weight Gain of HFS-fed Rats}

Body weight gain of HFS-fed rats treated with either mucilage (HFS-Ci250 and HFS-Ci500) or fenugreek galactomannan (HFS-Fg500) for 12 days (phase 2) is presented in Figure 1b. Both soluble fibers brought about significant reductions in body weight gain. However, mucilage at doses of 250 and $500 \mathrm{mg} / \mathrm{kg}$ was most effective in reducing body weight as it caused significant weight losses which appeared to be dose-dependent. 


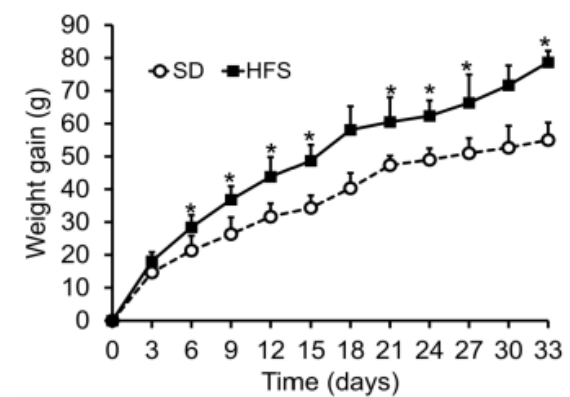

(a)

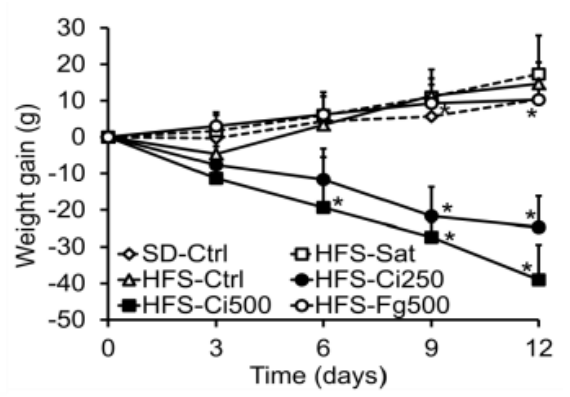

(b)

Figure 1. Body weight gain: (a) in rats fed a high-fat/high-sucrose diet (HFS) and those fed the standard diet (SD); (b) in HFS-fed rats treated with mucilage of C. inophyllum nuts at doses of 250 and $500 \mathrm{mg} / \mathrm{kg}$ (HFS-Ci250 and HFS-Ci500). For each time point, values labeled with a $*$ are significantly different from HFS (a; $t$-test) or HFS-Ctrl (b; DMRT) at $p<0.05$

\subsection{Effects of Mucilage Treatment on Biochemical Parameters in HFS-fed Rats}

Biochemical parameters investigated are presented in Figure 2 as well as in Table 2 and include the following: oral glucose tolerance, fasting plasma glucose, lipid profile, and atherogenic risk indices.

\subsubsection{Oral Glucose Tolerance}

During the oral glucose tolerance test (OGTT), postprandial plasma glucose variations were the same in all groups 30 minutes after glucose load (Figure 2a). However, postprandial plasma remained significantly higher in HFS-Ctrl and HFS-Ci250 groups 60 and 120 minutes after glucose load (Figure 2a). These groups also presented the highest values of total incremental plasma glucose (TIG) and relative glycemic index (RGI) as shown in Table 2. Treatment with mucilage at a dose of $500 \mathrm{mg} / \mathrm{kg}$ was effective in improving oral glucose intolerance by reducing TIG and RGI to values statistically similar to those obtained in SD-Ctrl and HFS-Fg500 groups (Table 2).

Table 2. Total incremental glucose (TIG) and relative glycemic index (RGI) during oral glucose tolerance test in HFS-fed rats treated with mucilage of C. inophyllum at doses of 250 and $500 \mathrm{mg} / \mathrm{kg}$ (HFS-Ci250 and HFS-Ci500)

\begin{tabular}{lll}
\hline Group & TIG $^{\mathbf{1}}(\mathbf{m g} / \mathbf{d l})$ & RGI $^{\mathbf{2}}(\boldsymbol{\%})$ \\
\hline SD-Ctrl & $97.66 \pm 25.48^{\mathrm{a}}$ & 100 \\
HFS-Ctrl & $175.00 \pm 19.15^{\mathrm{b}}$ & 179.19 \\
HFS-Sat & $96.00 \pm 24.98^{\mathrm{a}}$ & 98.30 \\
HFS-Ci250 & $164.50 \pm 16.26^{\mathrm{b}, \mathrm{c}}$ & 168.44 \\
HFS-Ci500 & $94.67 \pm 18.90^{\mathrm{a}}$ & 96.93 \\
HFS-Fg500 & $104.00 \pm 20.78^{\mathrm{a}, \mathrm{c}}$ & 106.49 \\
\hline
\end{tabular}

${ }^{1}$ Total incremental glucose: calculated for each rat as $T I G=\sum_{i=0}^{t}\left([\text { glycemia }]_{i}-[\text { glycemia }]_{0}\right)$

2Relative glycemic index: calculated for each group as $R G I=\frac{T I G_{x}}{T I G_{S D C t r l}} \times 100$

In the same column, values not sharing the same superscript letter are significantly different. $(p<0.05$, DMRT) 


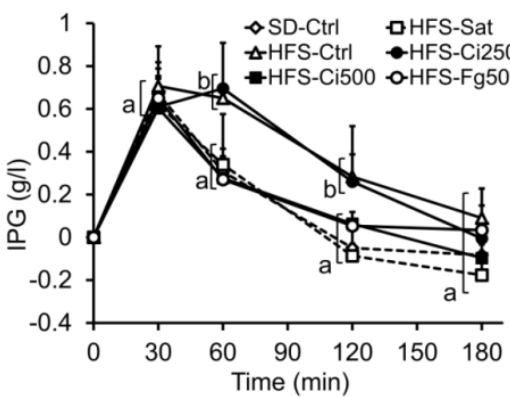

(a)

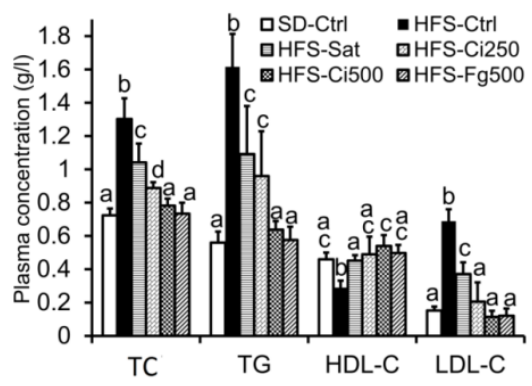

(c)

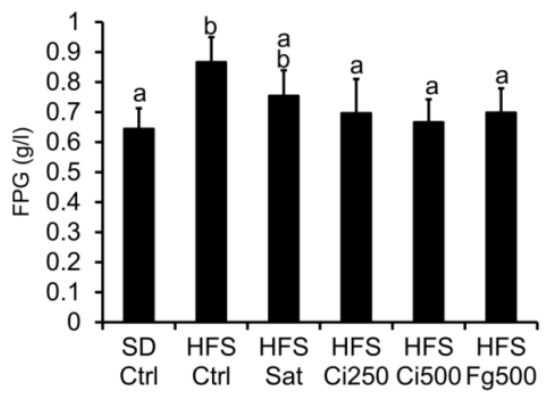

(b)

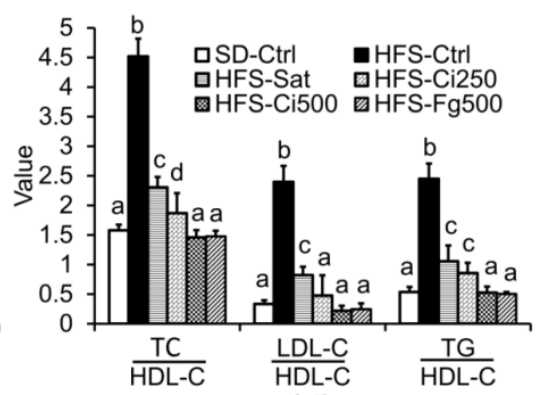

(d)

Figure 2. Biochemical parameters of rats fed a high-fat/high-sucrose diet (HFS) and treated with mucilage of $C$. inophyllum nuts at doses of 250 and $500 \mathrm{mg} / \mathrm{kg}$ (HFS-Ci250 and HFS-Ci500 respectively): (a) changes in plasma glucose concentration during oral glucose tolerance test; (b) fasting plasma glucose concentration; (c) lipid profile; (d) atherogenic risk indices. For each parameter or time point, values not sharing the same superscript

letter are significantly different at $p<0.05$ (DMRT). IPG: incremental plasma glucose; FPG: fasting plasma glucose; TC: total cholesterol; TG: triglycerides; HDL-C: HDL-cholesterol; LDL-C: LDL-cholesterol

\subsubsection{Fasting Plasma Glucose}

Figure $2 \mathrm{~b}$ presents fasting plasma glucose (FPG) of rats at the end of the study. FPG was significantly lower in all treated groups than in the HFS-Ctrl group $(p<0.05)$. However, FPG in the latter group remained in the normal physiological range.

\subsubsection{Lipid Profile}

The plasma lipid profile of rats is presented in Figure 2c. HFS-Ctrl rats had the highest values of total cholesterol (TC), triglycerides (TG), and LDL-cholesterol (LDL-C). Concentrations of TC, TG as well as LDL-C in mucilage-treated rats were significantly lower than those in the HFS-Ctrl group $(p<0.05)$ and comparable to those in the SD-Ctrl group. HDL-cholesterol concentrations were reduced in the HS-Ctrl group and mucilage-treated rats had HDL-C values close to those measured in the SD-Ctrl group. Cardiovascular risk indices calculated from lipid profile parameters are presented in Figure 2d. HFS diet consumption caused higher values of all cardiovascular risk indices in the positive control group (HFS-Ctrl). Indices values were reduced significantly by $500 \mathrm{mg} / \mathrm{kg}$ mucilage treatment at a point that they were comparable with those obtained in the negative control group (SD-Ctrl).

\section{Discussion}

This study aimed to assess the potential use of mucilage of Calophyllum inophyllum nuts as an effective agent in alleviating metabolic disturbances caused by a high-fat/high-sucrose diet in Wistar rats.

While it is rational to think that a balanced and diverse diet will cover the intake of most needed nutrients and that a diet with plentiful fruits and vegetables, nuts and milk is likely to be healthy, the fact is that globally, the intake of macronutrients such as carbohydrate and fats have dominated the 'risk-foods' controversy. According to the World Health Organization, a poor diet (high in fat or sugar) is a risk factor for non-communicable diseases and promotes overweight as well as obesity (WHO, 2010). Therefore, current healthy diet guidelines recommend a low-fat diet ( $<30 \%$ of energy) (WHO, 2018) and a restriction of free sugar in the diet to less than $5 \%$ of total energy intake (WHO, 2015). It has been shown that a high-carbohydrate and high-fat diet can induce excess body fat 
accumulation along with hypercholesterolemia and glucose intolerance in Wistar rats (Man \& He, 2009). The HFS diet used in our study had a $34.21 \%$ higher energy content than the standard laboratory diet (Table 1); the percentage calories from lipids and sucrose $(33.20 \%$ and $21.30 \%$ respectively) were above the amounts recommended by the World Health Organization. As a consequence, HFS diet consumption resulted in a $22.86 \%$ higher weight gain in rats (Figure 1). As suggested by other authors, the higher weight gain induced by HFS consumption is mainly the result of two metabolic processes: excess dietary fat storage (both central and peripheral) and endogenous lipogenesis from excess dietary carbohydrates (Man \& He, 2009; Foufelle \& Ferre, 2004). In our study, the high fat/high sucrose diet (HFS) had quite the same percentage of energy derived from carbohydrate intake as the standard diet (SD). An important difference between both diets was the percentage of energy derived from sucrose which was approximately 12 times higher in HFS than in SD (Table 1). These facts suggest that focus should not be made on the carbohydrate content of diet only but also on sucrose (or free sugars) content while assessing "risk nutrients" associated with metabolic syndrome (Ludwig, Hu, Tappy \& Brand-Miller J, 2018). However, measuring dietary exposure of human beings to sucrose or other free sugars remains a challenge as no reliable biomarker of free sugars intake has been identified (Prentice, 2018; Lampe et al., 2016). As a consequence, the relative contribution of free or added sugar to the incidence of obesity is still unknown, even though the relationship of fructose and sugar to risk factors for cardiovascular disease and fatty liver has been described recently (Prentice, 2018). HFS-fed rats tended to lose body weight significantly when treated with nut mucilage of Calophyllum inophyllum at doses of 250 and $500 \mathrm{mg} / \mathrm{kg}$ (Figure 2a). Such observation is an illustration of the weight-loss properties commonly attributed to soluble dietary fibers like mucilages and gums (Dakam et al., 2007; Boban et al., 2006; Enzi et al., 1980). It is recognized that the weight-loss properties of soluble fibers are closely linked to the viscosity when they are in contact with water molecules in the gut (Papathanasopoulos \& Camilleri, 2010). Viscosity in the gut results in delayed gastric emptying and produces a faster sensation of satiety that leads to decreased food and energy intakes (Marlett et al., 2002). Moreover, viscosity in the small intestine causes a reduction in the absorption of nutrients such as lipids and carbohydrates, thus limiting their bioavailability and their subsequent contribution to body fat storage (Foufelle \& Ferre, 2004; Marlett et al., 2002). Viscosity appears to be the main feature explaining the weight loss observed in rats treated with mucilage of $C$. inophyllum in our study.

Plasma postprandial glucose remained high till 120 minutes after glucose intubation in untreated HFS-fed rats with total incremental glucose 1.8 times higher than in SD-Ctrl rats during oral glucose tolerance test (OGTT). High and (or) persisting postprandial hyperglycemia characterizing glucose intolerance or poor glycemic control occurs early in the metabolic syndrome and type 2 diabetes (Petersen \& Schulman, 2006). Therefore, we may reasonably state that HFS diet in this study caused an impairment of glycemic control in rats. Glycemic control in humans and animals is achieved essentially by the action of two pancreatic hormones with antagonistic effects: glucagon (hyperglycemic) and insulin (hypoglycemic). In overweight or obese patients, glycemic control impairment is a result of insulin resistance (Petersen \& Schulman, 2006). Insulin resistance is characterized by a decrease in the sensitivity of peripheral tissues to insulin, mainly in striated skeletal muscle, liver, and adipose tissue as a result of steatosis caused by increased hepatic de novo fatty acids synthesis (Postic \& Girard, 2008; Petersen \& Schulman, 2006). As a consequence, the pancreas reacts by secreting more insulin which ensures temporary maintenance of blood glucose (Petersen \& Schulman, 2006). Over time, the increase in insulin production is no longer able to compensate for insulin resistance, leading to a marked increase in postprandial blood glucose levels (Petersen \& Schulman, 2006). Insulin resistance most often precedes type-2 diabetes which has a higher prevalence among overweight individuals (Field et al., 2001). In the present study, treatment with $C$. inophyllum nut mucilage improved glucose tolerance in HFS-fed rats especially at a dose of $500 \mathrm{mg} / \mathrm{kg}$ as evidenced by Figure 2a. Total incremental plasma glucose was reduced by $45.90 \%$ as compared with the HFS-Ctrl group during OGTT. Regular consumption of mucilages and other soluble dietary fibers has been linked to improved glycemic control due to their delaying effect in gastric emptying which reduces glucose bioavailability (Marlett et al., 2002).

Fasting plasma glucose (FPG) remained in the normal range in all HFS groups even though it was significantly higher in the HFS-Ctrl group (Figure 2b). Such observation was also made in other studies bearing on metabolic disturbances caused by a high fat and (or) high sucrose diets in rodents (Man \& He, 2009). Human studies showed that fasting blood glucose may remain normal or moderately high whereas blood glucose in the postprandial state is abnormally high in many patients with metabolic syndrome (Petersen \& Schulman, 2006). It has been hypothesized that fasting plasma glucose concentration may require a longer time to get affected by a high-fat/high-sucrose diet as the body primarily reacts to insulin resistance by compensatory mechanisms such as hyperinsulinism (Petersen \& Shulman, 2006). In the liver (which is responsible for 75 to $85 \%$ of post-absorptive glucose production), insulin resistance is characterized by endogenous overproduction of glucose which 
contributes to impairing glucose tolerance and increasing fasting plasma glucose (Gastaldelli et al., 2000).

Glycemic index has been defined as the area under the glucose response curve after consumption of $50 \mathrm{~g}$ carbohydrate from a test food divided by the area under the curve after consumption of $50 \mathrm{~g}$ carbohydrate from a control food, either white bread or glucose (Ludwig, 2000). Lowering the glycemic index of diet improves glycemic control, which results in lower blood glucose concentration throughout the day, and improves glucose tolerance (Brand-Miller et al., 2009; Liu et al. 2000). On the contrary, high glycemic index diets have been directly associated with an increased risk of cardiovascular diseases as well as type 2 diabetes (Brand-Miller et al., 2009; Liu et al. 2000). In our study, treatment of HFS-fed rats with nut mucilage led to significantly lower relative glycemic index (RGI) values than in untreated HFS rats (Table 2). This suggests a potential protective effect of nut mucilage against cardiovascular diseases and type 2 diabetes.

High fat/high sucrose diet (HFS) feeding resulted in significantly higher values of plasma lipids concentrations (total cholesterol, triglycerides, and LDL-cholesterol) as well as cardiovascular risk indices in rats (Figures 2c and 2d). Lipids in the body have two origins: exogenous (from the diet) and endogenous (synthesized by lipogenesis). Endogenous lipogenesis occurs mainly in the liver and the adipose tissue where it is 10 to 1000 times higher as compared to other tissues (Hillgartner, Salati \& Goodridge, 1995). Excess endogenous lipogenesis is a key contributor to obesity and MetS as it leads to excess body fat storage and increases the hepatic synthesis of cholesterol, triglycerides, and lipoproteins that are exported into the bloodstream (Foufelle $\&$ Ferre, 2004). The relationship between high-fat (and/or high-sucrose) diet consumption and impaired lipid profile has been evidenced over the years. HFS consumption results in markedly higher plasma concentrations of triglycerides and LDL-cholesterol in humans and rodents while HDL-cholesterol concentration is generally lower in such circumstances (Man \& He, 2009). In a human cohort study, increased carbohydrate intake was associated with lower HDL-cholesterol and higher triglycerides, total cholesterol-to-HDL cholesterol ratio as well as higher ApoB-to-ApoA1 ratio (Mente et al., 2017). In the present study, treatment of HFS-fed rats with nut mucilage was able to reduce plasma lipids concentration (TC, LDL-C, and TG) to a level comparable with that of rats fed the standard diet (SD) as shown in Figures $2 \mathrm{c}$ and $2 \mathrm{~d}$. Several dietary fibers have been reported to lower blood cholesterol levels, especially that fraction transported by low-density lipoproteins (LDL) (Marlett et al., 2002). Indeed, soluble fibers form a viscous matrix in the gut that traps bile acids and prevents their absorption from the ileum, thus increasing their fecal excretion (Marlett et al., 2002). As a result, LDL-cholesterol is removed from the bloodstream and converted into bile acids in the liver to replace those excreted in feces (Marlett et al., 2002). Over the past decades, some authors observed that soluble fibers-induced changes in the bile acid pool composition result in the reduction of endogenous cholesterol synthesis which is accountable for about $3 / 4$ of the total body cholesterol pool (Marlett et al., 1994; Hillman, Peters, Fisher \& Pomare, 1986). Yet, viscosity is not the only soluble fiber feature that affects lipid profile. In the colon, soluble fibers undergo fermentation by naturally-occurring microorganisms, and such fermentation process yields short-chain fatty acids such as acetic, propionic, and butyric acids which are known to inhibit hepatic synthesis of cholesterol and fatty acids (Lecumberri et al., 2007). Reduced concentrations of LDL-c in HFS rats treated with nut mucilage are one of the beneficial aspects of this study. This observation is in line with the calculated cardiovascular risk indices which were all attenuated following intervention with the mucilage treatment (figure 2d). Mucilage-treated rats also had higher values of plasma HDL-c concentration than untreated rats as shown in Figure 2c. In a recent study of hypolipidemic effects of Cordia dichotoma fruits mucilage in high fat diet-induced hyperlipidemic rats, El-Newary et al. (2017) also noticed such increase in HDL-c and hypothesized that this would be due to an increase in activity of lecithin cholesterol acyltransferase (LCAT). LCAT is an enzyme that plays a key role in blood lipids regulation by incorporating free cholesterol into HDL to form HDL-c which is uptaken by liver cells (El-Newary et al., 2017).

\section{Conclusion}

Our results suggest that mucilage obtained from Calophyllum inophyllum nuts is effective in attenuating metabolic syndrome (MetS) features such as excess body weight, high fasting blood glucose and lipids, as well as glucose intolerance in rats fed a high-fat/high-sucrose (HFS) diet. These findings may have applications in the management of the human metabolic syndrome. It is noteworthy that rats of the HFS-Sat group which were fed the HFS diet initially and the standard diet afterward had normal values for all the assessments performed in the present study. This highlights once more the importance of a balanced diet as a means to prevent or address MetS features.

\section{Acknowledgment}

The authors are grateful to Dr. Severin N. Tchameni, Faculty of Science, University of Douala, for technical 
assistance.

\section{Conflicts of Interest}

The authors declare that they have no conflict of interest.

\section{References}

Alberti, K. G., \& Zimmet, P. Z. (1998). Definition, diagnosis and classification of diabetes mellitus and its complications. Part 1: diagnostics and classification of diabetes mellitus Provisional report of a WHO consultation. Diabetes Medicine, 15, 539-553. https://doi.org/10.1002/(SICI)1096-9136(199807)15:7\%3C539::AID-DIA668\%3E3.0.CO;2-S

Alberti, K. G., Zimmet, P., \& Shaw, J. (2005). The metabolic syndrome: a new worldwide definition. Lancet, 366, 1059-1062. https://doi.org/10.1016/S0140-6736(05)67402-8

Bhalla, T. N., Saxena, R. C., \& Nigam, S. K. (1980). Calophyllolide, a new non-steroidal anti-inflammatory agent. Indian Journal of Medical Research, 72, 762-765.

Boban, P. T., Nambisan, B., \& Sudhakaran, P. R. (2006). Hypolipidaemic effect of chemically different mucilages in rats: a comparative study. British Journal of Nutrition, 96, 1021-1029. https://doi.org/10.1017/BJN20061944

Bonnet, F., \& Laville, M. (2005). Metabolic syndrome: definition, epidemiology, complications (in French). Spectra biologie, 145, 27-29.

Brand-Miller, J., McMillan-Price, J., Steinbeck, K., \& Caterson, I. (2009). Dietary glycemic index: health implications. Journal of the American College of Nutrition, 28(4), 446S-449S. https://doi.org/10.1080/07315724.2009.10718110

Butt, M. S., Shahzadi, N., Sharif, M. K., \& Nasir, M. (2007). Guar gum: a miracle therapy for hypercholesterolemia, hyperglycemia and obesity. Critical Reviews in Food Science and Nutrition, 47(4), 389-396. https://doi.org/10.1080/10408390600846267

Chan, T. F., Lin, W. T., Huang, H. L., Lee, C. Y., Wu, P. W., Chiu, Y. W., Huang, C. C., Tsai, S., Lin, C. L., \& Lee, C. H. (2014). Consumption of sugar-sweetened beverages is associated with components of the metabolic syndrome in adolescents. Nutrients, 6(5), 2088-2103. https://doi.org/10.3390/nu6052088

Chukwuma, C. I., Islam, M. S., \& Amonsou, E. O. (2018). A comparative study on the physicochemical, anti-oxidative, anti-hyperglycemic and anti-lipidemic properties of amadumbe (Colocasia esculenta) and okra (Abelmoschus esculentus) mucilage. Journal of Food Biochemistry, 42(5), e12601. https://doi.org/10.1111/jfbc.12601

Dakam, W., Kuate, D., Azantsa, B., \& Oben, J. (2009). Inhibitory effects of Glyphaea brevis Spreng. (Monach.) on pancreatic $\alpha$-amylase activity: Impact on postprandial blood glucose and weight control in rats. International Journal of Biomedical and Pharmaceutical Sciences, 3(1), 5-10.

Dakam, W., Shang, J., Agbor, G., \& Oben, J. (2007). Effects of sodium bicarbonate and albumin on the in vitro water-holding capacity and some physiological properties of Trigonella foenum graecum L. galactomannan in rats. Journal of Medicinal Food, 10(1), 169-174. https://doi.org/10.1089/jmf.2006.271

Damon, F. H. (2016). A Story of Calophyllum: From Ecological to Social Facts. Trees, Knots and Outriggers: Environmental Knowledge in the Northeast Kula Ring. Berghahn Books. p. 180-246. https://doi.org/10.2307/j.ctvswx6vz.9

Dehghan, M., Mente, A., Zhang, X., Swaminathan, S., Li, W., ... Mohan, V. (2017). Associations of fats and carbohydrate intake with cardiovascular disease and mortality in 18 countries from five continents (PURE): a prospective cohort study. The Lancet, 390(10107), 2050-2062. https://doi.org/10.1016/S0140-6736(17)32252-3

Divekar, V. B., Kalaskar, M. G., Chougule, P. D., Redasani, V. K., \& Baheti, D. G. (2010). Isolation and characterization of mucilage from Lepidium sativum Linn. seeds. International Journal of Pharma Research and Development, 2(1), 1-5.

Dweck, A. C., \& Meadows, T. (2002). Tamanu (Calophyllum inophyllum) - the African, Asian, Polynesian and Pacific Panacea. International Journal of Cosmetic Science, 24(6), 341-348. https://doi.org/10.1046/j.1467-2494.2002.00160.x

Eckel, R. H., Alberti, K. G., Grundy, S. M., \& Zimmet, P. Z. (2010). The metabolic syndrome. Lancet, 375, 
181-183. https://doi.org/10.1016/S0140-6736(09)61794-3

El-Newary, S. A., Sulieman, A. E. M., Asker, M. S., Mahmoud, M. G., \& El-Attar, S. R. (2017). Evaluation hypolipidemic and antioxidant characters of Cordia dichotoma fruits mucilage in high fat diet-induced hyperlipidemic rats. Der Pharma Chemica, 9(6), 20-29.

Enzi, G., Inelmen, E. M., \& Crepaldi, G. (1980). Effect of a hydrophilic mucilage in the treatment of obese patients. Pharmatherapeutica, 2(7), 421-428.

Field, A. E., Coakley, E. H., Must, A., Spadano, J. L., Laird, N., Dietz, W. H., ... Colditz, G. A. (2001). Impact of overweight on the risk of developing common chronic diseases during a 10-year period. The Archives of Internal Medicine, 161(13), 1581-1586. https://doi.org/10.1001/archinte.161.13.1581

Foufelle, F., \& Ferré, P. (2004). Nutrition, fat synthesis and obesity. In C. Remacle \& B. Reusens (Eds.), Functional foods, ageing and degenerative disease (pp. 260-277). Boca Raton, FL: CRC Press. https://doi.org/10.1533/9781855739017.2.260

Friedewald, W. T., Levy, R. I., \& Frederickson, D. S. (1972). Estimation of concentration of low density lipoprotein cholesterol in plasma without use of the ultracentrifuge. Clinical Chemistry, 18, 449-502. https://doi.org/10.1093/clinchem/18.6.499

Gastaldelli, A., Baldi, S., Pettiti, M., Toschi, E., Camastra, S., Natali, A., \& Ferrannini, E. (2000). Influence of obesity and type 2 diabetes on gluconeogenesis and glucose output in humans: a quantitative study. Diabetes, 49(8), 1367-1373. https://doi.org/10.2337/diabetes.49.8.1367

GBD Group. (2017). Life, death, and disability in 2016. The Lancet, 390(10100), 1083. https://doi.org/10.1016/s0140-6736(17)32465-0

Grundy, S. M., Cleeman, J. I., Daniels, S. R., Donato, K. A., Eckel, R. H., Franklin, B. A., ... Costa, F. (2005). Diagnosis and management of the metabolic syndrome: an American Heart Association/National Heart, Lung and Blood Institute scientific statement. Circulation, 112(17), 2735-2752. https://doi.org/10.1161/CIRCULATIONAHA.105.169404

Hieu, T. T., Kim, S. I., Kwon, H. W., \& Ahn, Y. J. (2010). Enhanced repellency of binary mixtures of Zanthoxylum piperitum pericarp steam distillate or Zanthoxylum armatum seed oil constituents and Calophyllum inophyllum nut oil and their aerosols to Stamoxys calcitrans. Pest Management Science, 66(11), 1191-1198. https://doi.org/10.1002/ps.1993

Hillgartner, F. B., Salati, L. M., \& Goodridge, A. G. (1995). Physiological and molecular mechanisms involved in nutritional regulation of fatty acid synthesis. Physiological reviews, 75(1), 47-76. https://doi.org/10.1152/physrev.1995.75.1.47

Hillman, L. C., Peters, S. G., Fisher, C. A., \& Pomare, E. W. (1986). Effects of fibre components pectin, cellulose, and lignin on bile salt metabolism and biliary composition in man. Gut, 27, 29-36. https://doi.org/10.1136/gut.27.1.29

Ishikawa, T. (2002). Anti HIV-1 active Calophyllum coumarins: distribution, chemistry and activity. Heterocycles, 53(2), 453-474. https://doi.org/10.3987/REV-99-526

Itoigawa, M., Ito, C., Tan, H. T. W., Kuchide, M., Tokuda, H., Nishino, H., \& Furukawa, H. (2001). Cancer chemopreventive agents, 4-phenylcoumarins from Calophyllum inophyllum. Cancer Letters, 169(1), 15-19. https://doi.org/10.1016/S0304-3835(01)00521-3

Kearney, J. (2010). Food consumption trends and drivers. Philosophical Transactions of the Royal Society B: biological sciences, 365(1554), 2793-2807. https://doi.org/10.1098/rstb.2010.0149

Kuo, L. E., Czarnecka, M., Kitlinska, J. B., Tilan, J. U., Kvetňanský, R., \& Zukowska, Z. (2008). Chronic stress with high-fat/high-sugar diet, shifts sympathetic signaling toward neuropeptide $\mathrm{Y}$ and leads to obesity and the metabolic syndrome. Annals of the New York Academy of Sciences, 1148, 232-237. https://doi.org/10.1196/annals.1410.035

Lampe, J. W., Huang, Y., Neuhouser, M. L., Tinker, L. F., Song, X., Schoeller, D. A., ... Prentice, R. L. (2016). Dietary biomarker evaluation in a controlled feeding study in women from the Women's Health Initiative cohort. The American Journal of Clinical Nutrition, 105(2), 466-475. https://doi.org/10.3945/ajcn.116.144840

Lecumberri, E., Goya, L., Mateos, R., Alia, M., Ramos, S., Izquierdo-Pulido, M., \& Bravo, L. (2007). A diet rich in dietary fiber from cocoa improves lipid profile and reduces malondialdehyde in hypercholesterolemic 
rats. Nutrition, 23, 332-341. https://doi.org/10.1016/j.nut.2007.01.013

Liu, S., Willett, W. C., Stampfer, M. J., Hu, F. B., Franz, M., Sampson, L., ... Manson, J. E. (2000). A prospective study of dietary glycemic load, carbohydrate intake, and risk of coronary heart disease in US women. The American Journal of Clinical Nutrition, 71(6), 1455-1461. https://doi.org/10.1093/ajcn/71.6.1455

Ludwig, D. S., Hu, F. B., Tappy, L., \& Brand-Miller, J. (2018). Dietary carbohydrates: role of quality and quantity in chronic disease. BMJ, 361, k2340. https://doi.org/10.1136/bmj.k2340

Madar, Z. (1989). The effect of acarbose and miglitol (BAY-M-1099) on postprandial glucose levels following ingestion of various sources of starch by nondiabetic and streptozotocin-induced diabetic rats. The Journal of Nutrition, 199, 2023-2029. https://doi.org/10.1093/jn/119.12.2023

Malik, V. S., Popkin, B. M., Bray, G. A., Després, J. P., Willett, W. C., \& Hu, F. B. (2010). Sugar-sweetened beverages and risk of metabolic syndrome and type 2 diabetes: a meta-analysis. Diabetes Care, 33(11), 2477-2483. https://doi.org/10.2337/dc10-1079

Man, Q., \& He, L. (2009). Effects of high-sugar and high-fat diet on growth and carbohydrate, lipid metabolism in Wistar rats. Wei sheng yan jiu= Journal of Hygiene Research, 38(6), 722-724.

Marlett, J. A., Hosig, K. B., Vollendorf, N. W., Shinnick, F. L., Haack, V. C., \& Story, J. A. (1994). Mechanism of serum reduction by oat bran. Hepatology, 20, 1450-1457. https://doi.org/10.1002/hep.1840200612

Marlett, J. A., McBurney, M. I., \& Slavin, J. L. (2002). Position of the American Dietetic Association: Health implication of dietary fiber. Journal of the American Dietetic Association, 102(7), 993-1000. https://doi.org/10.1016/S0002-8223(02)90228-2

McKee, T. C., Covington, C. D., Fuller, R. W., Bokesch, H. R., Young, S., Cardellina, J. H., ... Boyd, M. R. (1998). Pyranocoumarins from tropical species of the genus Calophyllum: a chemotaxonomic study of extracts in the National Cancer Institute collection. Journal of Natural Products, 61(10), 1252-1256. https://doi.org/10.1021/np980140a

Mente, A., Dehghan, M., Rangarajan, S., McQueen, M., Dagenais, G., Wielgosz, A., \& Yusuf, S. (2017). Association of dietary nutrients with blood lipids and blood pressure in 18 countries: a cross-sectional analysis from the PURE study. The Lancet Diabetes \& Endocrinology, 5(10), 774-787. https://doi.org/10.1016/S2213-8587(17)30283-8

NCEP. (2001). Executive summary of the third report of National Cholesterol Education Program (NCEP) expert panel on detection, evaluation and treatment of high blood cholesterol in adults (Adult Treatment Panel III). The Journal of the American Medical Association, 285, 2486-2497. https://doi.org/10.1001/jama.285.19.2486

Ngondi, J. L., Fossouo, Z., Djiotsa, E. J., \& Oben, J. (2006). Glyceamic variations after administration of Irvingia gabonensis seeds fractions in normoglycemic rats. African Journal of Traditional, Complementary and Alternative Medicines, 3(4), 94-101. https://doi.org/10.4314/ajtcam.v3i4.31181

Papathanasopoulos, A., \& Camilleri, M. (2010). Dietary fiber supplements: effects in obesity and metabolic syndrome and relationship to gastrointestinal functions. Gastroenterology, 138(1), 65-72. https://doi.org/10.1053/j.gastro.2009.11.045

Petersen, K. F., \& Schulman, G. I. (2006). Etiology of insulin resistance. The American Journal of Medicine, 119(5 Suppl.1), S10-S16. https://doi.org/10.1016/j.amjmed.2006.01.009

Postic, C., \& Girard, J. (2008). Contribution of de novo fatty acid synthesis to hepatic steatosis and insulin resistance: lessons from genetically engineered mice. The Journal of Clinical Investigation, 118(3), 829-838. https://doi.org/10.1172/JCI34275

Prentice, R. L. (2018). Intake biomarkers and the chronic disease nutritional epidemiology research agenda. The American Journal of Clinical Nutrition, 108(3), 433-434. https://doi.org/10.1093/ajcn/nqy206

Saxena, R. C., Nath, R., Palit, G., Nigam, S. K., \& Bhargava, K. P. (1982). Effect of calophyllolide, a nonsteroidal anti-inflammatory agent, on capillary permeability. Planta Medica, 44(4), 246-248. https://doi.org/10.1055/s-2007-971459

Schultes, R. E., \& Raffauf, R. F. (1990). The healing forest: medicinal and toxic plants of the Northwest Amazonia. Portland, Oregon: Dioscorides Press. p. 484. 
Singh, G. M., Micha, R., Khatibzadeh, S., Shi, P., Lim, S., ... Andrews, K. G. (2015). Global Burden of Diseases Nutrition and Chronic Diseases Expert Group (NutriCoDE). Global, regional, and national consumption of sugar-sweetened beverages, fruit juices, and milk: a systematic assessment of beverage intake in 187 countries. PloS one, 10(8), e0124845. https://doi.org/10.1371/journal.pone.0124845

Smith, M. (2003). Therapeutic applications of fenugreek. Alternative Medicine Review, 8(1), 20-27.

Spino, C., Dodier, M., \& Sotheeswaran, S. (1998). Anti-HIV coumarins from Calophyllum seed oil. Bioorganic \& Medicinal Chemistry Letters, 8(24), 3475-3478. https://doi.org/10.1016/S0960-894X(98)00628-3

Wood, D., De Backer, G., Faergeman, O., Graham, I., Mancia, G., \& Pyörälä, K. (1998). Prevention of coronary heart disease in clinical practice: Recommendations of the Second Joint Task Force of European and other Societies on Coronary Prevention. Atherosclerosis, 140(2), 199-270. https://doi.org/10.1016/S0021-9150(98)90209-X

World Health Organization. (2015). Guideline: sugars intake for adults and children. Geneva. p. 51.

World Health Organization. (2018). World Health Organization healthy diet fact sheet number 394. Retrieved from www.who.int/mediacentre/factsheets/fs394/en/

Xu, Z. Q., Hollingshead, M. G., Borgel, S., Elder, C., Khilevich, A., \& Flavin, M. T. (1999). In vivo anti-HIV activity of (+)-calanoide A in hollow fiber mouse model. Bioorganic \& Medicinal Chemistry Letters, 9(2), 133-138. https://doi.org/10.1016/S0960-894X(98)00713-6

Yimdjo, M. C., Azebaze, A. G., Nkengfack, A. E., Meyer, A. M., Bodo, B., \& Fomum, Z. T. (2004). Antimicrobial and cytotoxic agents from Calophyllum inophyllum. Phytochemistry, 65(20), 2789-2795. https://doi.org/10.1016/j.phytochem.2004.08.024

\section{Copyrights}

Copyright for this article is retained by the author(s), with first publication rights granted to the journal.

This is an open-access article distributed under the terms and conditions of the Creative Commons Attribution license (http://creativecommons.org/licenses/by/4.0/). 